\title{
Cronograma de cambios legislativos e institucionales en EE.UU. como consecuencia de desastres (1969-2004)
}

Claire B. Rubín, Irmak Renda-Tanali y William R. Cumming*

(Adaptación, nota introductoria y traducción de Francisco Javier Ruiz Martínez y Roberto Losada Maestre**)

Sweet are the uses of adversity, Which like the toad, ugly and venomous, Wears yet a precious jewel in his head.

W. SHAKeSPEAre. As you like it

\section{Nota introductoria}

Las crisis no son sólo momentos traumáticos; son además oportunidades para el cambio, para el aprendizaje. El cronograma que presentamos a continuación muestra los desastres, tanto aquellos producidos por fenómenos naturales, como aquellos debidos a la actividad humana (tecnológicos o industriales), que se han producido en los Estados Unidos desde 1969 hasta el año 2004. Junto a ellos aparecen los resultados de los mismos: estudios, políticas, legislación y cambios en las organizaciones.

La presentación gráfica de los desastres y la relación causal que los une a los productos políticos a que dan lugar, permite apreciar el modo en que las crisis, los acontecimientos traumáticos, permiten aprender. Siguiendo el esquema desarrollado por Vanaclocha, Martinón y Losada ${ }^{1}$, las crisis, los desastres, fomentan el aprendizaje y

* Disaster Research and Consulting. Proyecto patrocinado por ICF Consulting.

** Profesores de Ciencia Politica y de la Administración de la Universidad Carlos III de Madrid.. Tabajo realizado en el marco del Proyecto de Investigación VEM 2003-20035, financiado por el Ministerio de Ciencias y Tecnología..

${ }^{1}$ Vanaclocha, F. J., Martinón, R. y Losada, R. (2005), «Traumatic Renewal of Vales and Value Criteria in Crisis Management», Documentos de Trabajo Política y Gestión, 4. Madrid: Universidad Carlos III de Madrid. http://www.uc3m.es/uc3m/dpto/CPS/vml.pdf 
permiten adoptar políticas que implican costes elevados o no tienen una rentabilidad política apreciable, especialmente si se trata de poner en práctica lo aprendido de crisis distantes en el tiempo.

En el cronograma, además, puede apreciarse la veracidad de esta afirmación en lo que se refiere, de manera particular, a las políticas de prevención. La sensibilización provocada por el acontecimiento catastrófico hace que los distintos actores sociales demanden políticas de prevención. Así, vemos como a raíz de la inundación de Rapid City de 1972, se elaboró la Ley de Protección contra Pesastres provocados por Inundaciones; tras el vertido del Amocco Cadiz en 1978, nació la Ley de Seguridad de Puertos y Petroleros, otros tres vertidos ocurridos entre 1988 y 1991 (Ashland, Exxon Valdez y Phillips) originaron una nueva Ley, la de Contaminación por Petróleo, etc.

También queda reflejado que si, inmediatamente después de la crisis la agenda política está fuertemente marcada por los acontecimientos, la superación de la misma no supone el abandono de las políticas que se llevaron a cabo en ese momento. Por el contrario, existe un aprendizaje de tipo incremental que incorpora a la agenda política una serie de adquisiciones permanentes. El más evidente reflejo de ello es la creación de agencias destinadas a la prevención y la gestión de los desastres, como la EPA (Environmental Protection Agency) o la FEMA (Federal Emergency Managemet Agency).

Pero el interés de este cronograma va más allá, puesto que, él mismo, pasa a formar parte del proceso de aprendizaje derivado de las crisis provocadas por este tipo de desastres. En su artículo ya famoso, Kahneman y Tversky explican como la toma de decisiones en condiciones de incertidumbre (toma de decisiones heurística, no algorítmica) está sesgada por, entre otros factores, la disponibilidad de la información, es decir, «hay situaciones en las que la gente evalúa la frecuencia de una clase de acontecimientos o la probabilidad de un evento según la facilidad con la que ejemplos de los mismos pueden ser evocados por la mente» ${ }^{2}$. En este sentido el cronograma vendría a ser un modo de evitar ese sesgo, una forma de memoria histórica, que permite evaluar con precisión la probabilidad y frecuencia de los desastres, de cara a enfrentarse a futuros acontecimientos del mismo tipo.

Finalmente, si en el caso de los individuos resulta positivo escribir sobre las experiencias traumáticas que han padecido a lo largo de su vida dotándolas así de sentido³, reflejar los desastres padecidos por una nación a través de los años puede servir también como medio de superación del trauma que desencadenan, ayudando en la última de las tres etapas que atraviesa ese proceso ${ }^{4}$ : la de la reconexión con la vida cotidiana, enlazando el presente con el pasado que se ha visto interrumpido de manera repentina por el desastre 5 .

2 Tversky, A. y Kahneman, D. (1982), «Judgment under uncertainty: Heuristics and biases», en D. Kahneman, P. Slovic y A. Tversky, eds., Judgment under uncertainty: Heuristics and biases. Cambridge: Cambridge University Press, p. 11.

3 Pennebaker, J. (1997), Opening up: The healing power of expressing emotions. New York: Guilford, pp. 99-100.

${ }^{4}$ Herman J. L. (1992), Trauma and Recovery: The Aftermath of Violence. From Domestic Abuse to Political Terror. New York: Basic Books. Routledge.

5 Para Barbie Zelizer (2002) el periodismo cumple también esta función. Zelizer, B. (2002), Journalism after September 11. New York: 